\title{
FIRST OUTBREAK WITH CHIMERIC SWINE ENTERIC CORONAVIRUS (SeCoV) ON PIG FARMS IN SLOVAKIA - LESSONS TO LEARN
}

\author{
Rene MANDELIK ${ }^{1}$, Milan SARVAS ${ }^{2}$, Anna JACKOVA ${ }^{1}$, Slavomira SAlAMUnOVA ${ }^{1}$, \\ Jaroslav NOVOTNY ${ }^{1}$ and Stefan VILCEK ${ }^{1 *}$ \\ ${ }^{1}$ University of Veterinary Medicine and Pharmacy in Košice, Komenského 73, \\ 04181 Košice, Slovakia, ${ }^{2}$ Private veterinarian, Bojnice, Slovakia
}

(Received 22 March 2018; accepted 25 July 2018)

\begin{abstract}
This report describes the first disease outbreak caused by chimeric swine enteric coronavirus (SeCoV) on two pig farms in Slovakia in early 2015. The infection was introduced by import of two breeding boars which were placed in provisional quarantine in a unit not strictly separated from other healthy pigs in the same building. Subsequently, loss of appetite and diarrhoea were observed in both boars during the first three days in the isolation unit. The infection gradually spread to the farrowing area and throughout the farm in two weeks and later to another nearby farm. Yellow watery diarrhoea accompanied by dehydration and death was observed in piglets with a mortality ranging from 30 to $35 \%$. In the absence of an available vaccine, the pregnant sows were dosed by mouth with a $10 \%$ suspension prepared from the intestine and faeces of infected piglets in warm water. Three weeks after dosing, new litters of piglets were born which remained healthy with no development of diarrhoea.
\end{abstract}

Key words: Recombinant swine coronavirus, porcine epidemic diarrhoea virus, outbreak

Porcine coronaviruses, porcine epidemic diarrhoea virus (PEDV) and transmissible gastroenteritis virus (TGEV) cause serious enteric diseases in pigs. After the first PEDV infection had been detected in America in the 1970s, PEDV infection occurred also in Europe and Asia (Jung and Saif, 2015). The virus spread through the American continent, causing high economic losses. Recently outbreaks of PED have been documented in Western European countries, Slovenia and Ukraine. This epidemiological situation has challenged several laboratories to deeply analyse PEDV isolates. Research resulted in the identification of a novel chimeric swine enteric coronavirus $(\mathrm{SeCoV})$, in which most of the genome was derived from TGEV but the $\mathrm{S}$ gene encoding the spike protein originated from a PEDV genome. Such viruses were shown to be circulating in Italy (Boniotti et

\footnotetext{
*Corresponding author; E-mail: Stefan.Vilcek@uvlf.sk; Phone: 00421 (0) 915-984654
} 
al., 2016) and a very similar virus has been detected in Germany (Akimkin et al., 2016).

An outbreak due to infection of pigs by $\mathrm{SeCoV}$ was also confirmed in Slovakia in 2015. Here we describe the epidemiology of, and experience with, an outbreak on two farms in central Slovakia.

The outbreak started in early 2015 . The exact country of origin of the infection was not clear. The infection was introduced to a private pig farm A (550 sows, 7000 pigs) located in central Slovakia with two breeding boars originating from Norway. During their road journey to Slovakia they had changed transport in Germany and the Czech Republic. For lack of a separated quarantine unit on the farm the boars were housed in a provisional isolation unit linked with spaces for rearing gilts in the same stable. The attending persons moved among pigs on the farm with no attention to the possible transmission of infection. Three days after arrival both imported boars developed clinical signs of gastrointestinal tract disease characterised by loss of appetite and diarrhoea. The infection rapidly spread through the farm probably by the oro-faecal route and via service persons. The first animals to be affected were pre-farrowing sows and then all piglets in three farrowing areas. Rapid spread of infection was also observed in fattening pigs. The entire farm was infected within two weeks. Within 3-4 weeks the outbreak spread to another pig farm (farm B, 400 sows, 5500 pigs) with a different owner, which was located just $100 \mathrm{~m}$ away from farm A. The course of infection was similar to that described on farm A.

The clinical signs in the infected pigs were characterised by a loss of appetite for 3-5 days, with a return to normal feeding within 7 days. Vomiting occurred only in some litters, and sporadically in older animals. The disease was accompanied by elevated temperature. Yellow watery diarrhoea (Fig. 1A) was observed in cachectic piglets, accompanied by dehydration and death. Mortality in piglets was in the range of 30 to $35 \%$, but older animals survived. The intestinal tracts of dead piglets were filled with yellow watery faeces. An unusual behaviour of diseased piglets was that they laid on the sow's body and nestled closely to each other (Fig. 1B). In addition, reproductive disorders (abortions, poor conception) also occurred in sows.

Differential diagnosis excluded classical swine fever, African swine fever, rotavirus infection, colibacillosis, salmonellosis, dysentery, coccidiosis, and Trichuris suis infection. The laboratory analysis of rectal swabs and faeces from diseased piglets by RT-PCR with primers targeting the S gene of PEDV performed at the State Veterinary Institute in Jihlava, Czech Republic confirmed infection by PEDV. The same samples analysed at the DTU National Veterinary Institute in Lindholm, Kalvehave, Denmark further confirmed that pigs in Slovakia were infected with a novel chimeric swine enteric coronavirus, $\mathrm{SeCoV}$ (Belsham et al., 2016). 


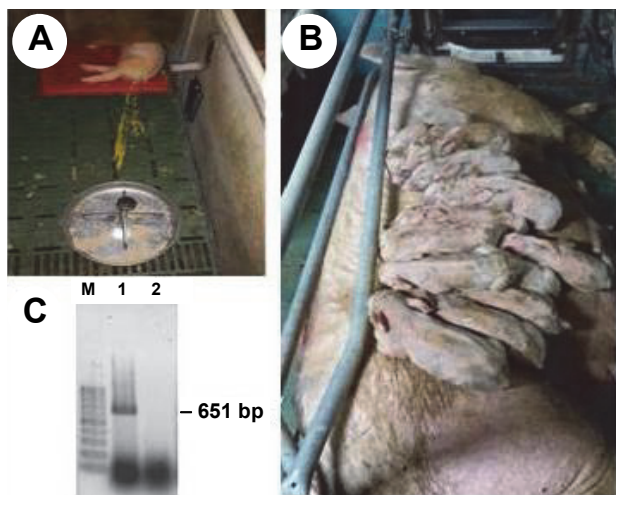

Fig. 1. Clinical manifestation of swine enteric coronavirus (SeCoV) infection in pigs. A - Yellow profuse watery diarrhoea in a piglet. B - Diarrhoeic piglets of retarded growth lying on the sow. $\mathrm{C}$ - Detection of virus by RT-PCR ( 651 bp DNA fragment) by primers selected from the S gene

(Kim et al., 2001). M - 100 bp marker, 1 - faeces from infected piglet, 2 - negative control

Adult pigs including the imported boars recovered from the infection in a week. To minimise economic losses in piglets, the first measure on the affected farm was the administration of rehydrating solutions and humic acids which stabilise the intestinal microflora in affected animals. Some piglets were fed with dried milk. Treatment with antibiotics was not successful. Due to the lack of a vaccine and the strong development of infection, the pregnant sows in the gestation area were dosed by mouth with a $10 \%$ suspension prepared from the intestine and faeces of infected piglets diluted in warm water. This exposure could theoretically improve lactogenic immunity of sows as had been experienced during a PEDV outbreak in Ukraine (Dastjerdi et al., 2015). Three weeks after application of the suspension new litters of piglets were born and remained healthy with no diarrhoea.

According to the official rules in Slovakia, imported animals must be placed into quarantine prior their introduction into the herds. The main problem with the first $\mathrm{SeCoV}$ outbreak in Slovakia was that the quarantine space was located in the same stable as breeding pigs. No doubt, the basic biosecurity measure for imported animals was seriously broken. On the other hand, it seems that infection with SeCoV or PEDV has not spread to other regions in Slovakia. Between 2015 and 2017 we tested 150 rectal swabs collected from diarrhoeic pigs of different ages on 15 pig farms in Slovakia by RT-PCR with primers selected from the S gene (Kim et al., 2001), which could also detect SeCoV (or PEDV) in faeces from the outbreak described in this work (Fig. 1C), and all samples were negative.

It should be mentioned that according to our information other boars from the same consignment were imported into Hungary. They were held for a long period in a quarantine station where the first signs similar to PED occurred. The 
correct quarantine prevented the spread of infection to pig farms. Nevertheless, an outbreak with a coronavirus occurred at the beginning of 2016 in a 60-sow farrow-to-finish pig farm in western Hungary. Genetic analysis has revealed that the pigs were not infected with $\mathrm{SeCoV}$ but with PEDV with some recombination in the S gene (Valkó et al., 2017). The PEDV strain from Hungary was closely related to PEDV strains circulating in Western Europe, Slovenia and Ukraine as shown by the grouping of their $\mathrm{S}$ gene sequences in the phylogenetic tree (Fig. 2).

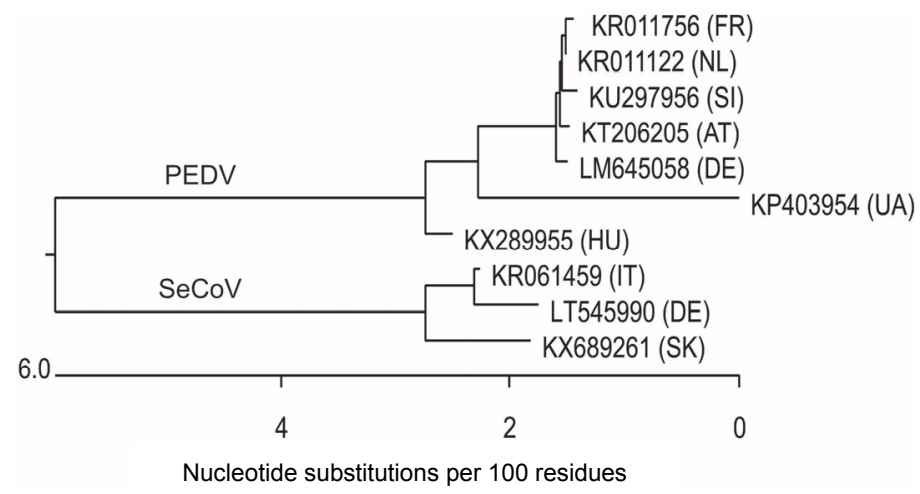

Fig. 2. Phylogenetic analyses of the S gene sequence (3941 bp DNA fragment) for selected SeCoV and PEDV strains identified in Europe. The tree was constructed by program MegAlign of DNASTAR Lasergene 8.1 package (Lasergene Inc., USA)

From an economic point of view, the treatment of diseased animals on affected farms with rehydration solutions and dried milk cost approximately $1000 € /$ farm. However, higher indirect costs were incurred due to the intensive care of sick piglets for 3 weeks and the 30-35\% mortality of piglets. In addition, during that period the liveweight gains of animals were reduced, the fattening period was extended by 4 to 6 weeks to slaughter, the growth of animals was retarded by $2-3$ months, and further losses (around 20-30\%) occurred because of reproductive problems. This disease outbreak emphasises the importance of applying strict biosecurity measures when importing new animals into a farm.

\section{Acknowledgement}

We would like to thank Peter Nettleton, Edinburgh for critical reading of the manuscript and correction of its English grammar. This study was realised by the projects APVV-15-0415 and Medical University Park in Košice (MediPark, Košice) ITMS: 26220220185 supported by the Operational Programme Research and Development (OPVaV-2012/2.2/08-RO) (Contract No. OPVaV/12/2013). 


\section{References}

Akimkin, V., Beer, M., Blome, S., Hanke, D., Hoper, D., Jenekel, M. and Pohlmann, A. (2016): New chimeric porcine coronavirus strain found in swine feces collected in Germany, 2012. Emerg. Infect. Dis. 22, 1314-1315.

Belsham, G. J., Rasmussen, T. B., Normann, P., Vaclavek, P., Strandbygaard, B. and Botner, A. (2016): Characterization of a novel chimeric swine enteric coronavirus from diseased pigs in Central Eastern Europe in 2015. Transbound. Emerg. Dis. 63, 595-601.

Boniotti, M. B., Papetti, A., Lavazza, A., Alborali, G., Sozzi, E., Chiapponi, C., Faccini, S., Bonilauri, P., Cordioli, P. and Marthaler, D. (2016): Porcine epidemic diarrhea virus and discovery of a recombinant swine enteric coronavirus, Italy. Emerg. Infect. Dis. 22, 83-87.

Dastjerdi, A., Carr, J., Ellis, R. J., Steinbach, F. and Williamson, S. (2015): Porcine epidemic diarrhea virus among farmed pigs, Ukraine. Emerg. Infect. Dis. 21, 2235-2237.

Jung, K. and Saif, L. J. (2015): Porcine epidemic diarrhea virus infection: etiology, epidemiology, pathogenesis and immunoprophylaxis. Vet. J. 204, 134-143.

Kim, S. Y., Song, D. S. and Park, B. K. (2001): Differential detection of transmissible gastroenteritis virus and porcine epidemic diarrhea virus by duplex RT-PCR. J. Vet. Diagn. Invest. 13, 516-520.

Valkó, A., Biksi, I., Cságola, A., Tuboly, T., Kiss, K., Ursu, K. and Dán, A. (2017): Porcine epidemic diarrhoea virus with a recombinant $\mathrm{S}$ gene detected in Hungary, 2016. Acta Vet. Hung. 65, 253-261. 